\title{
Optics and photonics education in central Florida
}

\section{David Hagan}

David J. Hagan, "Optics and photonics education in central Florida," Proc. SPIE 9663, Eighth International Topical Meeting on Education and Training in Optics and Photonics, 966311 (6 October 2003); doi: 10.1117/12.2208458

SPIE Event: Eighth International Topical Meeting on Education and Training in Optics and Photonics, 2003, Tucson, Arizona, United States 


\title{
Optics and photonics education in central Florida
}

\author{
David J. Hagan \\ Associate Director for Academic Programs, School of Optics/CREOL, University of Central Florida \\ P.O. Box 162700, 4000 Central Florida Boulevard, Orlando, Florida 32816-2700 \\ telephone: (407)823-6817; fax: (407)823-6880; e-mail: hagan@creol.ucf.edu
}

\begin{abstract}
We will describe several education programs that serve the growing optics industry in the Central Florida region, including the School of Optics' graduate programs and two-year and four-year programs in Photonics Technology taught by collaboration between the University of Central Florida and local community colleges.

(C)2003 Optical Society of America

OCIS codes: (000.2060) Education; (000.1200) Announcements, awards, news, and organizational activities
\end{abstract}

Since the founding of the Center for Research and Education in Optics and Lasers (CREOL) in 1986, the optics industry in Central Florida has grown significantly. Currently, the Central Florida optics industry consists of has slightly over 100 companies, with 16,000 employees and over $\$ 2$ billion in revenues. Along with this growth has come an increased need for knowledge of optics and photonics in the workforce.

One of the original reasons for founding CREOL was to aid Central Florida industry, and our philosophy is that the best way to do this is by developing an educated workforce. Initially, we focused on the graduate level, and optics tracks in Physics and Electrical Engineering MS and PhD programs were established. In 1998, after $37 \mathrm{PhD}$ and 96 MS graduates had emerged from these tracks, the University created a School of Optics, composed of the faculty members of CREOL, with its own graduate degree programs in Optics. To date, a total of $96 \mathrm{PhD}$ students and $180 \mathrm{MS}$ students have graduated in either Optics or one of the above tracks.

As the Central Florida optics industry grew, it has become apparent that there is a need for optics education programs below the graduate level, and particularly at the technician level. Recently a " $2+2$ " photonics technology program has been approved by the University of Central Florida. This program will be run out of the Engineering Technology program in the UCF College of Engineering, and links to the Photonics Technology Associates degree program at Valencia Community College. In the initial phases, some of the laboratory facilities for this program are being provided by the School of Optics.

In this presentation, we will describe these programs in detail, as well as other optics education and outreach programs throughout the Central Florida region. We will also describe how these programs run in collaboration through the Florida Photonics Cluster. 